\title{
$\mathrm{Cs}_{2} \mathrm{AgBiX}_{6}(\mathrm{X}=\mathrm{Br}, \mathrm{Cl})$ - New visible light absorbing, lead-free halide perovskite semiconductors
}

Eric T. McClure ${ }^{\dagger}$, Molly R. Ball ${ }^{\ddagger}$, Wolfgang Windl ${ }^{\ddagger}$, and Patrick M. Woodward ${ }^{\dagger} *$

${ }^{\ddagger}$ Department of Materials Science and Engineering, The Ohio State University, 2041 College Road, Columbus, Ohio 43210, United States

${ }^{\dagger}$ Department of Chemistry and Biochemistry, The Ohio State University, 100 W. 18th Avenue, Columbus, Ohio 43210, United States

\section{Electronic Structure Calculations}

A comparison of the calculated geometry optimized lattice parameters compared with the experimental lattice parameters is given in Table S1.

Table S1. An HSC hybrid functional with spin orbit coupling was used for the computations.

\begin{tabular}{|c|c|c|c|}
\hline Compound & $\begin{array}{c}\text { Space Group } \\
\text { Symmetry }\end{array}$ & Experimental & Calculated \\
\hline $\mathrm{CH}_{3} \mathrm{NH}_{3} \mathrm{PbCl}_{3}$ & $P m-3 m$ & 5.70 & 5.64359 \\
\hline $\mathrm{Cs}_{2} \mathrm{AgBiCl}_{6}$ & $F m-3 m$ & $10.7774(2)$ & 10.7768 \\
\hline $\mathrm{CH}_{3} \mathrm{NH}_{3} \mathrm{PbBr}_{3}$ & $P m-3 m$ & 5.94 & 5.98378 \\
\hline $\mathrm{Cs}_{2} \mathrm{AgBiBr}_{6}$ & $F m-3 m$ & $11.2711(1)$ & 11.2712 \\
\hline
\end{tabular}




\section{Kubelka Munk Plots}

The diffuse reflectance plots have been transformed into psdeudo absorbance using the Kubelka Munk transformation as shown in Figure S1.
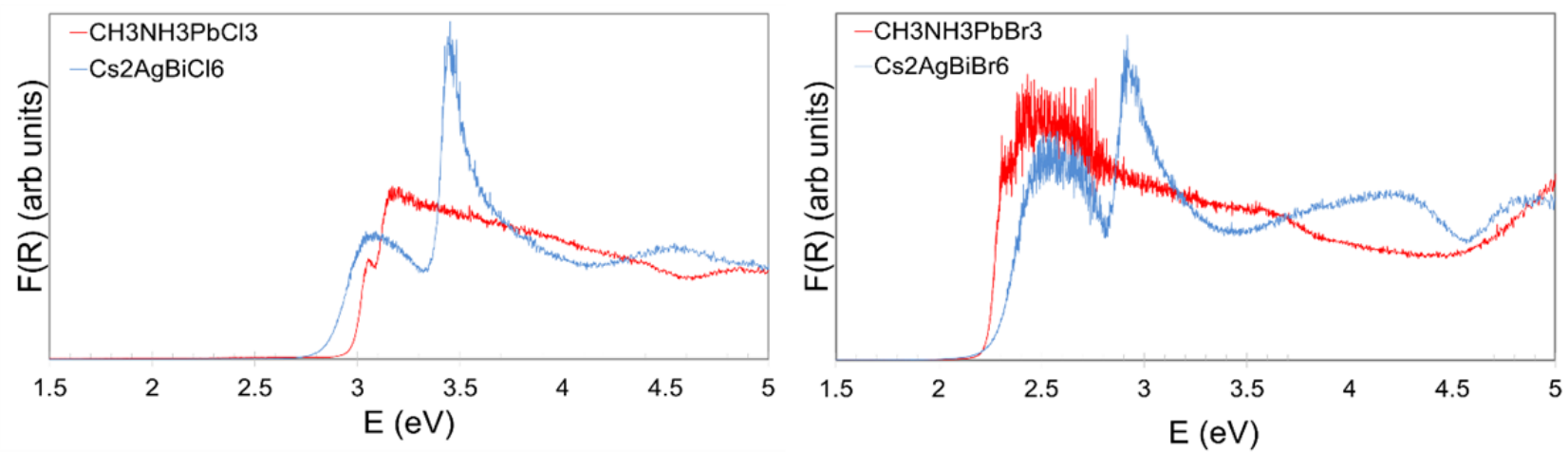

Figure S1. Kubleka-Munk plots for the silver-bismuth (blue) and lead compounds (red), with chloride compounds the left and bromide compounds on the right. 


\section{Light and Moisture Stability}

Plots of the X-ray powder diffraction patterns of the $\mathrm{Cs}_{2} \mathrm{AgBiCl}_{6}$ and $\mathrm{Cs}_{2} \mathrm{AgBiBr}_{6}$ samples after exposure to air in the dark for 2 weeks, exposure to both air and light for 2 weeks and for 4 weeks are shown in Figure s2.
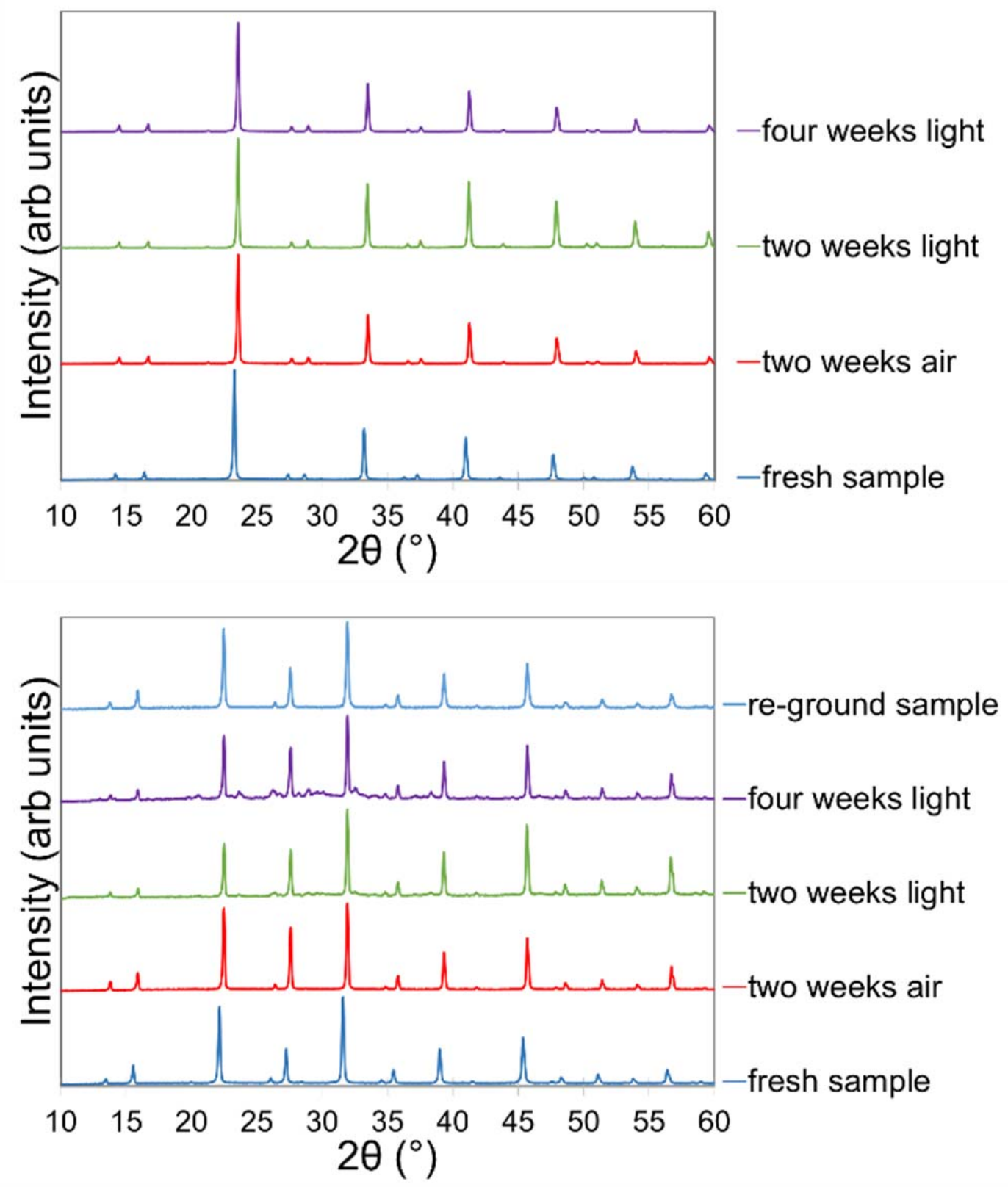

Figure S2. XRPD overlays of $\mathrm{Cs}_{2} \mathrm{AgBiCl}_{6}$ (upper) and $\mathrm{Cs}_{2} \mathrm{AgBiBr}_{6}$ (lower) showing the light stability of the compounds after a month of exposure to sunlight. The change in the powder diffractogram for the bromine compound indicates that structural changes are accompanying the visual darkening of the pigment. 